\title{
Utdatert kunnskapsgrunnlag for betablokkere etter hjerteinfarkt?
}

\author{
Behandling med betablokkere etter hjerteinfarkt er basert på studier fra tidlig i 1980-årene. Siden den gang \\ er diagnostikken av hjerteinfarkt blitt mer sensitiv, revaskularisering har bedret overlevelsen og det er kom- \\ met bedre medikamenter for sekundærprofylakse. Vi mener derfor det er på tide med ny forskning og at indi- \\ kasjonen for rutinemessig betablokkerbehandling etter hjerteinfarkt bør revurderes.
}

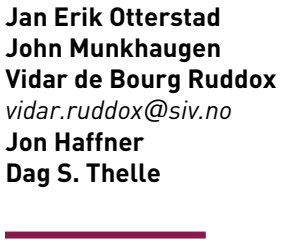

e-tab 3 og e-tab 4 finnes i Tidsskriftets elektroniske utgaver

Allerede i 2007 ble det påpekt (1) at behandling med betablokkere etter hjerteinfarkt bygger på tre studier fra 1981-82 (2-4) (tab 1). De kliniske manifestasjonene av et hjerteinfarkt er de samme nå som tidlig i 1980-årene, men både diagnostikk, behandling og pasientpopulasjon er endret. Innføring av høysensitive troponinmålinger har endret diagnostikken. Både patogenesen og behandlingseffekten kan være annerledes nå enn tidligere, bl.a. fordi den relative fordelingen av ulike årsaksfaktorer har forandret seg. En pasient med akutt hjerteinfarkt i 1970-årene var ofte en røyker, slank og med forhøyet totalkolesterol. I $2015 \mathrm{er} \mathrm{det}$ en overvektig, prediabetisk ikke-røykende person med lavt HDL-kolesterol og høye triglyseridnivåer. Tidligere var venstre ventrikkel-remodellering etter store hjerteinfarkter et stort problem og innebar tap av kontraktilt vev etterfulgt av dilatasjon av venstre ventrikkel og redusert ejeksjonsfraksjon med utvikling av hjertesvikt. I dag er slike infarkter sjeldnere, siden de fleste pasienter blir revaskularisert tidlig og overlever infarktet med velbevart hjertefunksjon. Er det overhodet samme sykdom vi står overfor?

Effekten av enhver behandling avhenger av utgangspunktet $\mathrm{i}$ forhold til hva som er maksimalt oppnåelig og hva som er nedre grense for et klinisk relevant resultat. Redusert effekt kan enten skyldes at behandlingen bare virker når det er en viss relativ fordeling av årsaksfaktorene, eller at de faktorene som påvirkes allerede er tilnærmet maksimalt redusert.
Nye prevalensdata viser at et stort antall koronarpasienter står på betablokkerbehandling flere år etter infarktet. Dette gjelder begge kjønn, de eldste og yngste samt pasienter med og uten hjertesvikt.

I The NOR-COR Study for Coronary Prevention ble bruk av betablokker etter et hjerteinfarkt, utført perkutan koronar intervensjon (PCI) eller aortokoronar bypassoperasjon registrert ved utskrivning og etter en oppfølgingstid på 1,7 år (5) (tab 2). Forskrivning av betablokker var på henholdsvis $85 \%$ og $72 \%$, samsvarende med tall fra den store europeiske registerstudien EUROASPIRE IV (6). Er kunnskapsgrunnlaget for rutinemessig betablokkerbehandling etter hjerteinfarkt god nok?

\section{Hva sier nyere studier?}

I et enkelt litteratursøk fant vi ingen større studier med oppfølging $\geq$ tre måneder hos pasienter med normal venstre ventrikkelejeksjonsfraksjon.

Studien Clopidogrel and Metoprolol in Myocardial infarction Trial (COMMIT) ( $\mathrm{n}=45852$ pasienter, metoprolol versus placebo innen 24 timer, fire ukers oppfølging) viste ingen effekt på total død, og en reduksjon av reinfarkt og ventrikkelflimmer ble oppveiet av økt risiko for kardiogent sjokk (7). Videre har betablokkere ikke vist effekt på kardiovaskulære hendelser hos pasienter med stabil koronarsykdom (8).

To nyere registerstudier har aktualisert problemstillingen:

I den største studien, basert på registeret Reduction of Atherothrombosis for Continued Health (REACH), ble i 2003-04 44708 pasienter inkludert fra allmennpraksis (9) (e-tab 3). Disse var fra 44 land fra hele verden, og $31 \%$ hadde tidligere hjerteinfarkt. Etter en oppfølgingsperiode på 3,6 år var det ingen forskjell i kardiovaskulære dødsfall mellom pasienter med og uten betablokkere når man brukte tilbøyelighetsanalyse (propensity score matching), en analyse hvor det retrospektivt forsøkes å utligne forskjeller i to grupper (e-tab 4).

CORonariens stables en region NORd-
pas-de-Calais (CORONOR-studien) omfattet 4184 pasienter fra Nord-Frankrike, hvorav 2612 (62\%) hadde gjennomgått infarkt (10). Oppfølgingstiden var på to år, og man så en statistisk signifikant reduksjon i kardiovaskulære dødsfall. Antallet hendelser var få, og type 2-feil kan derfor ikke utelukkes. Statistisk metode var den samme som for studien basert på REACH.

CORONOR- og REACH-studiene ledsages av kommentarer av hhv. Floyd (11) og Danchin \& Laurent (12). Her tas svakheter ved studiene opp. Ikke-brukere av betablokkere kan ha sluttet pga. bivirkninger eller ha hatt kontraindikasjoner som påvirker prognosen. Type betablokker og indikasjon for behandlingen er ukjent og det er ikke opplyst om venstre ventrikkelfunksjon. Det konkluderes med at man trenger mer forskning.

En metaanalyse av randomiserte, kontrollerte studier inkluderte 102003 pasienter fra 60 studier, hvorav 12 var publisert i revaskulariseringsperioden (1991-2013) (13). Betablokkere hadde ingen effekt på død, mens 30 dagers insidens av residivinfarkt og angina ble redusert på bekostning av økt forekomst av hjertesvikt og kardiogent sjokk. De øvrige 48 studiene var publisert i prerevaskulariseringsperioden (1966-99), da betablokkere reduserte både dødelighet, hjerteinfarkt og angina.

En annen, fersk metaanalyse inkluderte 10 observasjonsstudier av behandling med betablokkere etter et PCI-behandlet infarkt (14). 25168 pasienter hadde fått betablokkere og 15705 var uten slik behandling. Det primære endepunktet var total død. I justerte analyser ble denne redusert med betablokkere, men effekten var bare til stede i studiepopulasjoner med redusert ejeksjonsfraksjon og med lavt forbruk av øvrig medisinsk sekundærprofylakse. Det var ingen effekt på kardiale dødsfall, nytt hjerteinfarkt eller sykehusinnleggelser for hjertesvikt. Forfatterne konkluderer med at det nå ikke er bevis for rutinemessig betablokkerbehandling av alle med hjerteinfarkt, og at nye studier må til for å avklare dette nærmere. 
Tabell 1 Langtidsstudier på postinfarktbehandling med betablokkere. GMT = Gothenburgh Metoprolol Trial; NTS = Norwegian Timolol Study; BHAT $=$ The $\beta$-blocker Heart Attack Trial; VV EF = Venstre ventrikkel ejeksjonsfraksjon; gj.sn. = gjennomsnitt; i.a. = ikke angitt; $\mathrm{md} .=$ måneder. CAPRICORN = Carvedilol Post-infarct Survival Control in LV dysfunction study; RR = Relativ risiko

$\begin{array}{cccc}\text { GMT, } n=1395 & \text { NTS, } n=1884 & \text { BHAT, } n=3838 & \text { CAPRICORN, } n=1959 \text { fra 2001 } \\ \text { fra 1981 (3) } & \text { fra } 1981(2) & \text { fra 1982 (4) } & \text { Pasienter med VVEF }<4 \% \text { (5) }\end{array}$

Behandling/oppfølging

$\begin{array}{lcccc}\text { Medikament } & \text { Metoprolol } & \text { Timolol } & \text { Propranolol } & \text { Karvedilol } \\ \text { Tid fra infarkt til inklusjon (gj.sn.) } & <48 \text { timer (11 } \pm 3) & 6-27 \text { dager (14) } & 5-12 \text { dager (14) } & 3-21 \text { dager (i.a.) } \\ \text { Initialt intravenøst } & 15 \mathrm{mg} \text { ved innleggelse } & \text { nei } & \text { nei } & \text { nei } \\ \text { Postinfarkt måldose } & 100 \mathrm{mg} \times 2 & 10 \mathrm{mg} \times 2 & 60-80 \mathrm{mg} \times 3^{1} & 25 \mathrm{mg} \times 2 \\ \text { Tid til måldose } & 2 \mathrm{~d} \varnothing \mathrm{gn} & 2 \mathrm{~d} \varnothing \mathrm{gn} & 2 \mathrm{~d} \varnothing \mathrm{gn} & 4-6 \text { uker } \\ \text { Gj.sn. oppfølging ( min.-maks) } & 3 \mathrm{md} \text {. (i.a.) } & 17 \text { md. (12-33) } & 25 \text { md (i.a.) } & 15 \text { md. (i.a.) }\end{array}$

Ledsagende behandling

Trombolyse/primær PCI

nei

i.a.

i.a.

Antikoagulasjon

ACE-hemmer

Statin

Mortalitetsreduksjon

1 Pasienter med serum-propranolol $\geq 20 \mathrm{mg} / \mathrm{l}$ på $80 \mathrm{mg} \times 3$ fikk redusert dosen til $60 \mathrm{mg} \times 3$ på fire ukers visitt $(82 \%)$

$\begin{array}{ccc}\text { nei } & \text { nei } & \text { nei } \\ \text { nei } & \text { nei } & \text { nei } \\ 6 \%(p<0,03) & \text { RR } 45 \%(p<0,001) & \text { RR } 27 \%(p<0,00 \\ \text { g } \times 3 \text { fikk redusert dosen til } 60 \mathrm{mg} \times 3 \text { på fire ukers visitt }(82 \%)\end{array}$

$\begin{array}{lcc}\text { nei } & \text { nei } & 45 \% \\ \text { i.a. } & 22 \% & 86 \% \\ \text { i.a. } & 9 \% & \text { i.a. } \\ \text { nei } & \text { nei } & 98 \% \\ \text { nei } & \text { nei } & \text { i.a. } \\ \%(p<0,001) & \text { RR } 27 \%(p<0,005) & H R 0,77(0,60-0,98)(p=0,03)\end{array}$

\section{Internasjonale retningslinjer}

I de europeiske retningslinjene for behandling av stabil koronarsykdom fra 2013 anføres det at effekten av betablokkere er usikker fordi studiene på postinfarktpasienter ble gjort før implementering av annen sekundærprofylaktisk behandling (15).

Fra samme år ble det påpekt i tilsvarende retningslinjer for ST-elevasjonsinfarkt at langtidsbehandling med betablokkere er veletablert, men at usikkerhetsmomentene gjengitt over ble støttet (16).

I retningslinjene for ikke-ST-elevasjonsinfarkt fra 2015 anbefales tidlig betablokkerbehandling til pasienter med pågående iskemiske symptomer der det ikke er kontraindikasjoner (17). Pasienter uten alvorlig hjertesvikt kan tilbys langtidsbehandling.

I amerikanske retningslinjer fra 2012 påpekes det at betablokkere er effektive hos pasienter som har hatt hjerteinfarkt innen de siste tre år og/eller har venstre ventrikkel-dysfunksjon (18).

\section{Bivirkninger}

Ofte kommuniserte bivirkninger av betablokkere er tretthet, nedsatt fysisk yteevne, søvnvansker, livstruende bradyarytmi og hypotensjon (15). Imidlertid har en nylig utført kritisk gjennomgang vist at bare fem av 33 beskrevne bivirkninger (hyperglykemi, diaré, svimmelhet, intermitterende klaudikasjon og bradykardi) var hyppigere hos betablokkerbehandlede enn andre (19).

Allikevel er opplevde bivirkninger plagsomme og deres natur kan maskere annen sykdom, som dermed kan forbli udiagnostisert over lengre tid.

\section{Skal nåtidens pasienter ha betablokkere?}

Diagnostiske kriterier, initial behandling og oppfølging av hjerteinfarkt har endret seg drastisk siden 1980-årene. Med det store antallet som bruker betablokkere, vil problemstillinger rundt bivirkninger og maskering av annen sykdom være høyaktuell. Behandlingen må derfor være basert på resultater fra prospektive, randomiserte studier utført på en aktuell pasientpopulasjon.

For nåtidens postinfarktpasienter foreligger det ingen slik dokumentasjon. Tiden bør være moden for å utføre en studie på pasienter som er optimalt behandlet etter dagens standard. Et sentralt eksklusjonskriterium må være større infarkter som predisponerer for venstre ventrikkel-remodellering hvor både angiotensinkonvertasehemmer og betablokker er indisert uansett.

\section{Jan Erik Otterstad (f. 1944)}

er dr.med. og spesialist i indremedisin og i kardiologi. Han er seniorkonsulent og leder av Senter for Hjerteforskning ved Sykehuset i Vestfold og emeritus Fellow of the European Society of Cardiology.

Forfatter har fylt ut ICMJE-skjemaet og oppgir ingen interessekonflikter.

\section{John Munkhaugen (f. 1983)}

er ph.d. og konstituert overlege ved Medisinsk avdeling, Drammen sykehus. Han er utdanningskandidat i kardiologi, postdoktorforsker i Vestre Viken og prosjektleder for NOR-COR (NORwegian CORonary Prevention)- studien, et tverrfaglig forskningsprosjekt innen sekundærforebyggende behandling og oppfølging ved koronar hjertesykdom ved Drammen sykehus og Sykehuset i Vestfold i samarbeid med Universitetet i Oslo.

Forfatter har fylt ut ICMJE-skjemaet og oppgir ingen interessekonflikter.

\section{Vidar de Bourg Ruddox (f. 1976)}

er ph.d., konstituert overlege ved Hjerteseksjonen, Klinikk medisin, Sykehuset i Vestfold HF. Han er utdanningskandidat i kardiologi og postdoktorforsker.

Forfatter har fylt ut ICMJE-skjemaet og oppgir ingen interessekonflikter. 
Tabell 2 Andel pasienter i NOR-COR-studien som brukte betablokkere ved henholdsvis utskrivning og oppfølgingsvisitt. NSTEMI = hjerteinfarkt uten ST-heving, STEMI = hjerteinfarkt med ST-heving

\section{Utskrivning, $\%$}

85

Oppfølging, $\% 1$

Alle, $\mathrm{N}=1127$

\section{Kjønn}

Menn, $n=890$

85

84

72

Kvinner, $\mathrm{n}=237$

Alder, år

$$
<60, \mathrm{n}=364
$$

$60-75, n=625$

$>75 n=138$

Tid siden indeksopphold

8 uker -6 md., $n=233$

$6-12$ md., $n=242$

74

$12-24$ md., $n=347$

24-36 md., $n=305$

\section{Diagnose ved utskrivning}

NSTEMI, $n=561$

STEMI, $\mathrm{n}=335$

892

74

Stabil koronarsykdom, $n=231$

82

75

\section{Angiografi ved indeksopphold}

Åpne kar/veggforandringer, $\mathrm{n}=69$

$74^{2}$

$4^{2}-61$
2

Enkarsykdom, $\mathrm{n}=622$

84

72

Flerkarsykdom, $\mathrm{n}=435$

71

73

74
$88-75$

\section{Revaskularisering ved indeksopphold}

Perkutan koronar intervensjon, $n=748$

84

$91^{2}$

\section{3}

$86^{2}$

81

83

$90^{2}$

Aortokoronar bypass, $\mathrm{n}=126$
${ }^{1}$ Alle $p$-verdier for forskjeller ved utskrivning versus inklusjon var signifikante $\left.1<0,001\right)$

2 Forskjeller $\mathrm{i}$ undergrupper ved utskrivning og ved inklusjon: $p<0,05$

${ }^{3}$ Forskjeller $i$ undergrupper ved utskrivning og ved inklusjon: $p<0,01$

\section{Jon Haffner (f. 1940)}

er dr.med., spesialist i generell kirurgi og i gastroenterologisk kirurgi og professor emeritus.

Forfatter har fylt ut ICMJE-skjemaet og oppgir ingen interessekonflikter.

\section{Dag S. Thelle (f. 1942)}

er spesialist i indremedisin og professor emeritus fra Avdeling for biostatistikk, Institutt for medisinske basalfag, Universitetet i Oslo og Sahlgrenska akademin, Göteborgs universitet. Han er gjesteforsker ved Nasjonalt folkehelseinstitutt og medredaktør i European Journal of Epidemiology.

Forfatter har fylt ut ICMJE-skjemaet og oppgir ingen interessekonflikter.

\section{Litteratur}

1. Otterstad JE, Platou ES, Mangschau A et al. Hjerteinfarkt. Diagnostikk og behandling. Hjerteforum 2007: 20 (suppl 1): 51-2.

2. The Norwegian Multicenter Study Group. Timololinduced reduction in mortality and reinfarction in patients surviving acute myocardial infarction. N Engl J Med 1981; 304: 801-7.

3. Hjalmarson A, Elmfeldt D, Herlitz J et al. Effect on mortality of metoprolol in acute myocardial infarction. A double-blind randomised trial. Lancet $1981 ; 2: 823-7$

4. B-blocker Heart Attack Trial Research Group. A randomized trial of propranolol in patients with acute myocardial infarction. I. Mortality results. JAMA 1982; 247: 1707-14.

5. Munkhaugen J, Sverre E, Peersen K et al. The role of medical and psychosocial factors for unfavourable coronary risk factor control. Scand Cardiovasc J 2016; 50: 1-8.

6. Kotseva K, Wood D, De Bacquer D et al. EUROASPIRE IV: A European Society of Cardiology survey on the lifestyle, risk factor and therapeutic management of coronary patients from 24 European countries. Eur J Prev Cardiol 2015; 0: 1-13.

7. COMMIT (CLOpidogrel and Metoprolol in Myocardial Infarction Triall collaborative group. Early intravenous then oral metoprolol in 45852 patients with acute myocardial infarction: randomized placebo-controlled trial. Lancet 2005; 366: 1622-32.

8. Huang HL, Fox KAA. The impact of beta-blockers on mortality in stable angina: a meta-analysis. Scott Med J 2012; 57: 69-75.

9. Bangalore $S$, Steg $G$, Deedwania P et al. $\beta$-Blocker use and clinical outcomes in stable outpatients with and without coronary artery disease. JAMA 2012; 308: 1340-9.

10. Bauters C, Lemesle G, Meurice T et al. Prognostic impact of $\beta$-blocker use in patients with stable coronary artery disease. Heart 2014: 100: 1757-61.

11. Floyd JS. $\beta$-blockers for secondary prevention in stable coronary artery disease: can observational studies provide valid answers? Heart 2014; 100 : $1741-2$.

12. Danchin N, Laurent S. Coronary artery disease. Are $\beta$-blockers truly helpful in patients with CAD? Nat Rev Cardiol 2013; 10: 11-2.

13. Bangalore $S$, Makani $H$, Radford $M$ et al. Clinical outcomes with $\beta$-blockers for myocardial infarction: a meta-analysis of randomized trials. Am J Med 2014; 127: 939-53.

14. Huang B-T, Huang FY, Zuo Z-L et al. Meta-analysis of relation between oral $\beta$-blocker therapy and outcome in patients with acute myocardial infarction who underwent percutaneous coronary intervention. Am J Cardiol 2015; 115: 1529-38. 
15. The Task Force on the management of stable coronary artery disease of the European Society of Cardiology. 2013 ESC guidelines on the management of stable coronary artery disease. Eur Heart J 2013; 34: 2949-3003.

16. Steg PG, James SK, Atar D et al. ESC Guidelines for the management of acute myocardial infarction in patients presenting with ST-segment elevation. Eur Heart J 2012; 33: 2569-619.

17. Roffi M, Patrono C, Collet JP et al. 2015 ESC Guide lines for the management of acute coronary syndromes in patients presenting without persistent ST-segment elevation: Task Force for the Management of Acute Coronary Syndromes in Patients Presenting without Persistent ST-Segment Elevation of the European Society of Cardiology (ESC). Eur Heart J 2016: 37: 267-315

18. 2012 ACCF/AHA/ACP/AATS/PCNA/SCAI/STS guidelines for the diagnosis and management of patients with stable ischemic heart disease. Circulation 2012: 126: 354-471.

19. Barron AJ, Zaman N, Cole GD et al. Systematic review of genuine versus spurious side-effects of beta-blockers in heart failure using placebo control: recommendations for patient information. Int J Cardiol 2013; 168: 3572-9.

Mottatt 9.9. 2015, første revisjon innsendt 12.11. 2015, godkjent 29.2. 2016. Redaktør: Martine Rostadmo.

Engelsk oversettelse på www.tidsskriftet.no 